\title{
Nanocomposite Hydrogen-Bonded Multilayer Ultrathin Films by Simultaneous Sexithiophene and Au Nanoparticle Formation
}

Derek Patton, Jason Locklin, Matthew Meredith, Yu Xin, and Rigoberto Advincula*1

${ }^{1}$ Department of Chemistry, University of Houston, Houston, TX 77204

* To whom correspondence should be addressed. Email: radvincula@uh.edu

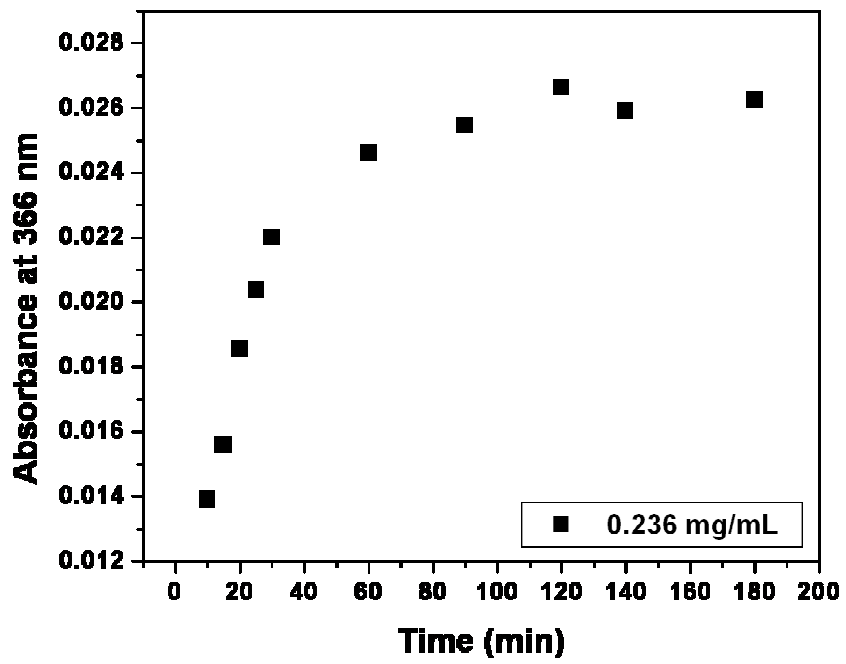

Figure S1. Growth in the absorbance of PVP3T as a function of adsorption time. 


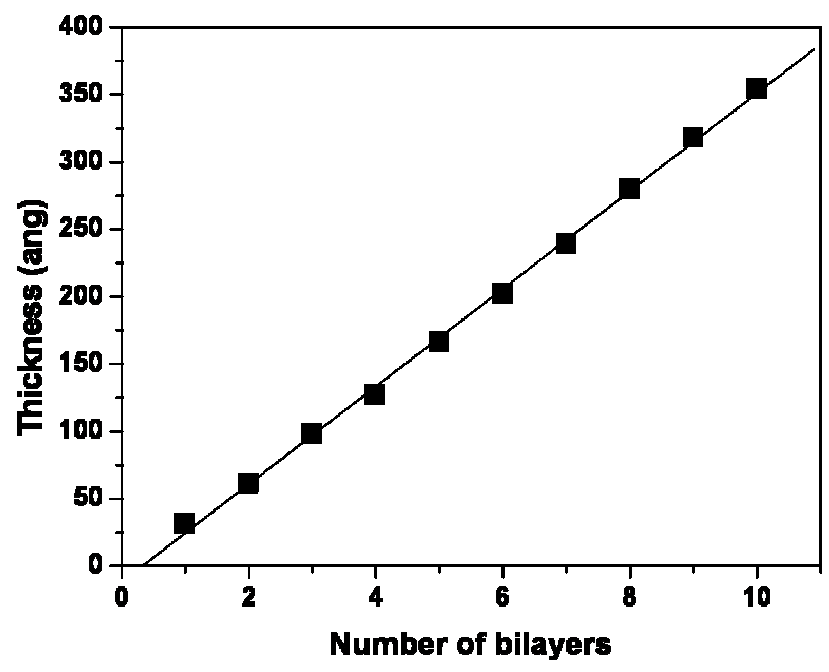

Figure S2. Thickness increase of PVP3T/PAA multilayers with increasing layer number determined by ellipsometry.

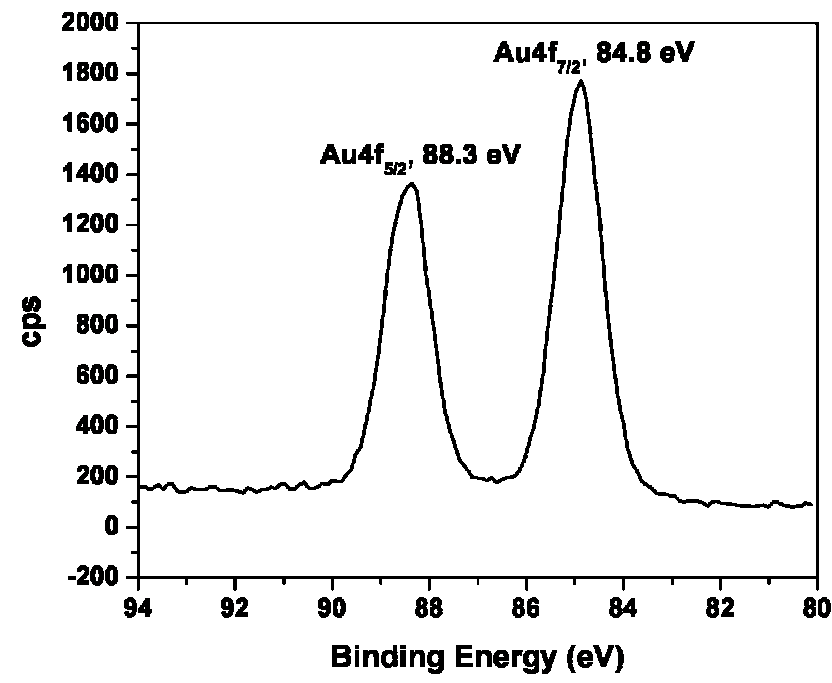

Figure S3. Au4f photoelectron spectra showing the characteristic peaks of metallic Au at 84.8 and $88.3 \mathrm{eV}$. Spectrum was obtained from PVP3T/PAA film after $72 \mathrm{hrs}$ under reaction conditions. 
Supporting Information (Patton et al.)

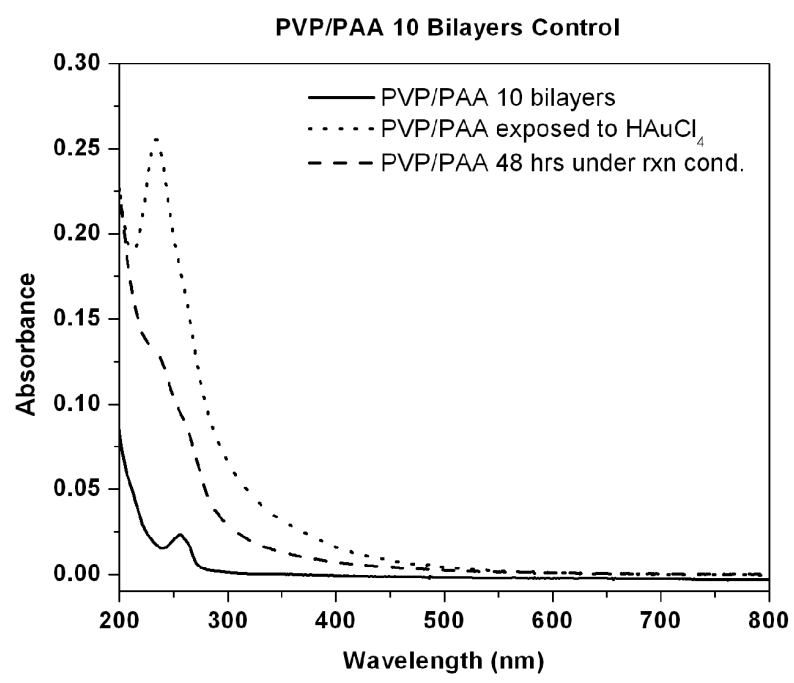

Figure S4. $\mathrm{P}_{4} \mathrm{VP} / \mathrm{PAA}$ (no terthiophene) multilayer thin film loaded with $\mathrm{HAuCl}_{4}$ and exposed to the same reaction conditions as previously described. In the absence of $3 \mathrm{~T}$, no surface plasmon band was observed indicating the gold precursor is not thermally reduced. 